\title{
Evaluation of Performance and Emission Characteristics of Biodiesel Fuel Produced from Rapeseed Oil
}

\author{
Momar Talla Dieng ${ }^{1,2}$, Takumi Iwanaga ${ }^{1}$, Yokoyama Christie Yurie ${ }^{1}$ and Shuichi Torii ${ }^{1}$ \\ 1. Department of Advance Mechanical System Engineering, Kumamoto University, Kurokami, 2-39-1, Kumamoto 860-8555, Japan \\ 2. Laboratoire de Photonique Quantique d'Energie et de Nano Fabrication, Faculté des Sciences et Techniques, Université Cheikh \\ Anta Diop de Dakar (UCAD), Dakar-Fann Dakar, B.P. 5005, Sénégal
}

\begin{abstract}
The objective of the present study is to examine and compare the performance and emission characteristic of two biodiesel fuels produced from rapeseed oil via transesterification method. Tested biodiesel fuels (ROME (Rapeseed Oil Methyl Ester) and ROEE (Rapeseed Oil Ethyl Ester)) were selected based on their properties obtained from an optimization of transesterification conditions. A Yanmar diesel engine has led to evaluating their performance parameters such as fuel consumption rate, exhaust gas temperature and emission characteristic corresponding to nitrogen oxides $\left(\mathrm{NO}_{x}\right)$, carbone monoxide $(\mathrm{CO})$ and carbon dioxide $\left(\mathrm{CO}_{2}\right)$. A comparative analysis was carried out using normal diesel fuel tested in same experimental conditions. Fuel consumption rate was measured by observing the volumetric rate from the fuel tank of the engine supported by stopwatch. The exhaust gas temperature and emission characteristic were measured simultaneously by using a testo 350 flue gas analyzer. According to the results, biodiesel fuels showed a higher fuel consumption rate and exhaust gas temperature under an increase of engine speed. They also exhibited lower $\mathrm{NO}_{x}$ emission with a slight rise in $\mathrm{CO}$ and $\mathrm{CO}_{2}$ emission compared to mineral diesel fuel. ROME exhibited low emission gas compared to ROEE and mineral diesel. It can be evaluated as a promising alternative fuel for diesel engine.
\end{abstract}

Key words: Biodiesel, transesterification reaction, rapeseed oil, diesel engine, emission characteristics.

\section{Nomenclature}

ROME Rapeseed Oil Methyl Ester (biodiesel obtained from rapeseed oil by using methanol)

ROEE Rapeseed Oil Ethyl Ester (biodiesel obtained from rapeseed oil by using ethanol)

HHV Higher Heating Value

ISO International Organization for Standardization

ATSM American Society for Testing and Materials

FGT Flue Gas Temperature

$\mathrm{NO}_{\mathrm{x}} \quad$ Nitrogen Oxides

NO Nitric Oxide

$\mathrm{NO}_{2} \quad$ Nitrogen Dioxide

$\mathrm{CO}$ Carbone Monoxide

$\mathrm{CO}_{2} \quad$ Carbone Dioxide

\section{Introduction}

Diesel engine constitutes the most cost effective internal combustion engine used in engineering machinery for power generation [1]. A vast majority of

Corresponding author: Momar Talla Dieng, M.Sc., research field: mechanical systems engineering. these engines are engaged in transportation (road, railway, naval, etc.) and electricity generation. This gives rise to their important role in the global economy moving [2]. Fossil fuels are commonly used to run diesel engine due to its high thermal efficiency. The energy generated from the combustion of these fuels leads to an excellent engine performances. However, they simultaneously generate harmful emission gas such as $\mathrm{CO}_{2}$ (carbon dioxide), $\mathrm{CO}$ (carbon oxide), $\mathrm{NO}_{x}$ (nitrogen oxides), and PM (particular matters) which threat the sustainability of our ecosystem by environmental pollution and global warming [3-5]. Besides, the high energy demand combined with the limited petroleum reserves leads to the fast depletion of fossil fuels with expectation about 40 years [6].

These are key factors that motivated research and development for alternative diesel fuel with maximum efficiency and minimum environmental pollutions criteria. In this context, biodiesel can be considered as 
the most feasible options thanks to its renewability and compliance with fuel standard [7, 8]. It can be obtained from biological sources such as vegetable oil, animal fat, algae and recycling cooking oil. These raw materials contain triglycerides molecules which are converted into fatty acid alkyl ester (biodiesel) by using a specific reaction called transesterification. This is a chemical process involving triglycerides with alcohol in the presence of a catalyst to yield biodiesel and glycerol as by-product [9-13]. The properties of the biodiesel depend strongly on this reaction and are strictly checked before its use in diesel engine. Nevertheless, the incomplete combustion of biodiesel in diesel engine releases harmful gas through the atmosphere. Among them, $\mathrm{CO}, \mathrm{CO}_{2}$, and $\mathrm{NOx}$ are widely emitted. These emission gases are generally analyzed and compared to those from normal diesel in order to evaluate the viability of the synthesized biodiesel. In this line of investigation, many researches considered that $\mathrm{CO}$ emissions are reduced when diesel engine is fueled by pure biodiesel [14-16]. Experiments was carried out by Kalligeros et al. [17] and Usta et al. [18] to estimate the emission characteristic of biodiesel fuels produced from sunflower oil and tobacco seed oil respectively. Their results reveal that a low $\mathrm{CO}$ emission was noticed from produced fuels [17, 18]. Many alcohol types are used in biodiesel production (methanol, ethanol, etc.). Their nature can influence the $\mathrm{CO}$ emission. Particularly, biodiesel based methyl esters emitted less CO compared to those based on ethyl esters [19]. On the other hand, biodiesel fuels are considered to emit low $\mathrm{CO}_{2}$ compared to mineral diesel with 50\%-80\% reduction in $\mathrm{CO}_{2}$ emissions [20]. In fact, biodiesels are lower-carbon fuels and have lower elemental carbon-to-hydrogen ratio than diesel [21,22]. However, in some case, $\mathrm{CO}_{2}$ emissions from them are found more important compared to normal diesel fuels. This can be explained by the high combustion efficiency of diesel fuels $[23,24]$. As for $\mathrm{NO}_{x}$ emission, some investigations found out an increase of this gas when using biodiesel to fuel diesel engine.
Nevertheless, Utlu and Kocak [25] and Hansen et al. [26] have noticed a decreasing trend of this gas from their researches. Some reasons are given to explain the complexity of $\mathrm{NO}_{x}$ emission. Many researchers believe that the oxygen content in biodiesel is responsible for this tendency of high $\mathrm{NO}_{x}$ emission. However, Lapuerta et al. [27] found that the oxygen content in biodiesel has no influence on $\mathrm{NO}_{x}$ emission. Recent studies still show an effective reduction of these harmful gases when using biodiesel as an alternative to diesel fuels [28-30].

Therefore, consideration must be taken regarding fuels quality of biodiesel for better estimation of these emission gases. This quality characteristic is expressed by the fuels' properties of biodiesel which can be controlled by the transesterification process. Thus, the objective of this present study is to investigate the engine performance and emission characteristics of two biodiesel samples (ROME (Rapeseed Oil Methyl Ester) and ROEE (Rapeseed Oil Ethyl Ester)) obtained from rapeseed oil by transesterification reaction. Data obtained are analyzed to evaluate their quality as alternative for regular diesel and to confirm the efficiency of transesterification strategy used.

\section{Materials and Method}

\subsection{Fuel Properties}

Biodiesels used in this study were obtained from rapeseed oil by transesterification process. The reaction involved methanol and ethanol to produce ROME and ROEE, respectively. The transesterification conditions were optimized based on the variation of the molar ratio of alcohol to rapeseed oil and alcohol type while other reaction parameters were kept constant. Each fuel produced was tested for compliance with ASTM (American Society for Testing and Materials) standards for density, viscosity and high heating value then compared to those of mineral diesels. From this optimization process, the optimal transesterification reaction conditions which give the best fuel properties were found to be an alcohol/oil molar ratio of $18: 1,1 \%$ 
of potassium hydroxide as catalyst, 30 min of reaction time, $60{ }^{\circ} \mathrm{C}$ of reaction temperature and stirring speed of $650 \mathrm{rpm}$. ROME and ROEE produced with these conditions present good fuel properties where ROME gives the best results. Both of them were used in the engine test. Mineral diesel was also tested in same condition to provide comparative data. Properties of these tested fuels are listed in Table 1, which are taken from the previous study [31].

\subsection{Engine Test}

Engine test was performed by using a Yanmar diesel engine TF70V-E model as shown in Fig. 1. Its specifications are given in Table 2 .

Test was performed outdoors at ambient temperature of $32{ }^{\circ} \mathrm{C}$ and $29 \%$ of humidity. During each test, the engine was fully warmed up for $30 \mathrm{~min}$ prior to the beginning of data collection. The engine power was adjusted by the engine speed varied for 1,000, 1,500 and 2,000 rpm. A digital tachometer HT-5500 was used to measure the engine speed. Between each test, the fuel tank was completely drained and rinsed several times with the fuel for the next test. Each experiment was repeated three times to calculate the mean values. All data are obtained after the engine has reached a steady operation. Fuel consumption rate was measured by observing the volumetric rate from the fuel tank supported by stopwatch. The exhaust gas temperature and emission characteristic from the biodiesel were analyzed simultaneously by using a testo 350 Flue gas analyzer made by TESTO, Inc (from Germany). The gas analyzer was connected to the end of engine's chimney as shown in the experimental set up (Fig. 2) and its specifications are given in Table 3 .

Table 1 Properties of the test fuels.

\begin{tabular}{llll}
\hline Samples & $\begin{array}{l}\text { Density } \\
\left(15^{\circ} \mathrm{C} ; \mathrm{g} / \mathrm{mL}\right)\end{array}$ & $\begin{array}{l}\text { Kinematic viscosity } \\
\left(40{ }^{\circ} \mathrm{C} ; \mathrm{mm}^{2} / \mathrm{s} ; 15 \mathrm{~s}^{-1}\right)\end{array}$ & $\begin{array}{l}\text { High heating value } \\
(\mathrm{MJ} / \mathrm{kg})\end{array}$ \\
\hline ROME & 0.865 & 3.49 & 40.81 \\
ROEE & 0.853 & 4.50 & 39.94 \\
Diesel & 0.806 & 2.50 & 45.44 \\
\hline
\end{tabular}

Table 2 Diesel engine specification.

\begin{tabular}{ll}
\hline Engine model & TF70V-E \\
\hline Engine type & 4 -stroke diesel engine \\
Maximum output & $5.5 \mathrm{~kW} / 2,600 \mathrm{~min}^{-1}$ \\
Continuous rate output & $4.8 \mathrm{~kW} / 2,600 \mathrm{~min}^{-1}$ \\
Total stroke volume & $0.382 \mathrm{~L}$ \\
\hline
\end{tabular}

Table 3 Gas analyzer specifications.

\begin{tabular}{lll}
\hline Measurement item & Measurement range & Resolution \\
\hline $\mathrm{CO}_{2}$ & $0-25$ vol.\% & $0.01 \mathrm{vol} \%$ \\
$\mathrm{CO}, \mathrm{H}_{2}$-compensated & $0-10,000 \mathrm{ppm}$ & $1 \mathrm{ppm}$ \\
$\mathrm{NO}$ & $0-4,000 \mathrm{ppm}$ & $1 \mathrm{ppm}$ \\
$\mathrm{NO}_{2}$ & $0-500 \mathrm{ppm}$ & $0.1 \mathrm{ppm}$ \\
$\mathrm{SO}_{2}$ & $0-5,000 \mathrm{ppm}$ & $1 \mathrm{ppm}$ \\
$\mathrm{H}_{2} \mathrm{~S}$ & $0-300 \mathrm{ppm}$ & $0.1 \mathrm{ppm}$ \\
$\mathrm{CO}_{2}$-(IR) & $0-50$ vol.\% & $0.01 \mathrm{vol} \%(0 \sim 25$ vol.\%) \\
& Natural gas: $100-40,000 \mathrm{ppm}$ & $0.1 \mathrm{vol} \%(>25$ vol. $\%)$ \\
$\mathrm{HC}$ & Propane: & $10 \mathrm{ppm}$ \\
& $100-21,000 \mathrm{ppm}$ & $10 \mathrm{ppm}$ \\
$\mathrm{K}$-type (NCr-N) & Butane: & $10 \mathrm{ppm}$ \\
S-type (Pt10Rh-Pt) & $100-18,000 \mathrm{ppm}$ & $0.1{ }^{\circ} \mathrm{C}$ \\
\hline
\end{tabular}




\section{Results and Discussion}

\subsection{Effect of Biodiesel on Fuel Consumption Rate}

Fuel consumption rate is a parameter used to estimate the long-term viability of fuel during engine operation. Fig. 3 shows the evolution of fuel consumption rate of fuels with the variation of engine speed. It can be seen that for any tested fuel, the fuel consumption rate increases with the increase of engine speed. In fact, when the engine speed is increased the friction horsepower increased according to the drop in the mechanical efficiency to maintain a fixed torque output thus leading to more fuel consumption [32]. By using biodiesel fuels, the engine fuel consumption rate is higher compared to when using mineral diesel. This difference can be explained by the low energy content of biodiesel compared to normal diesel (Table 1) [33, 34].

As the result, a larger amount of biodiesel fuel must be supplied to the engine to attain the same engine power output as that of conventional diesel. At low and medium engine speed (1,000 and 1,500 rpm), the fuel consumption rate of ROEE is slightly higher than that of ROME because of the slight differences in their fuels properties. However, at high engine speed this difference disappeared as shown in Fig. 3.

\subsection{Effect of Biodiesel on FGT (Flue Gas Temperature)}

The FGT or exhaust gas temperature gives an indication about the combustion temperature. Its variation can influence the amount of exhausted pollutants from the burning fuel [35]. From Fig. 4, there is an increase in FGT with increase of engine speed for all fuels. In fact, diesel engine usually consumes more fuels to maintain a constant torque output when its speed is increased. Consequently, this releases more heat and hence increases the FGT [36]. Most of works of the literature stated that higher FGT is obtained when using biodiesel compared to other diesel fuel [37]. However, lower values are recorded for ROME during the experiment (Fig. 4). This can be attributed to the fact that, compared to mineral diesel, ROME exhibits higher latent heat of vaporization and lower heating value. Thus, more heat is needed for ROME vaporization, while the energy released by this biodiesel is lower than from the same mass of mineral diesel. As the result, the low FGT values for ROME can be considered as acceptable [38].

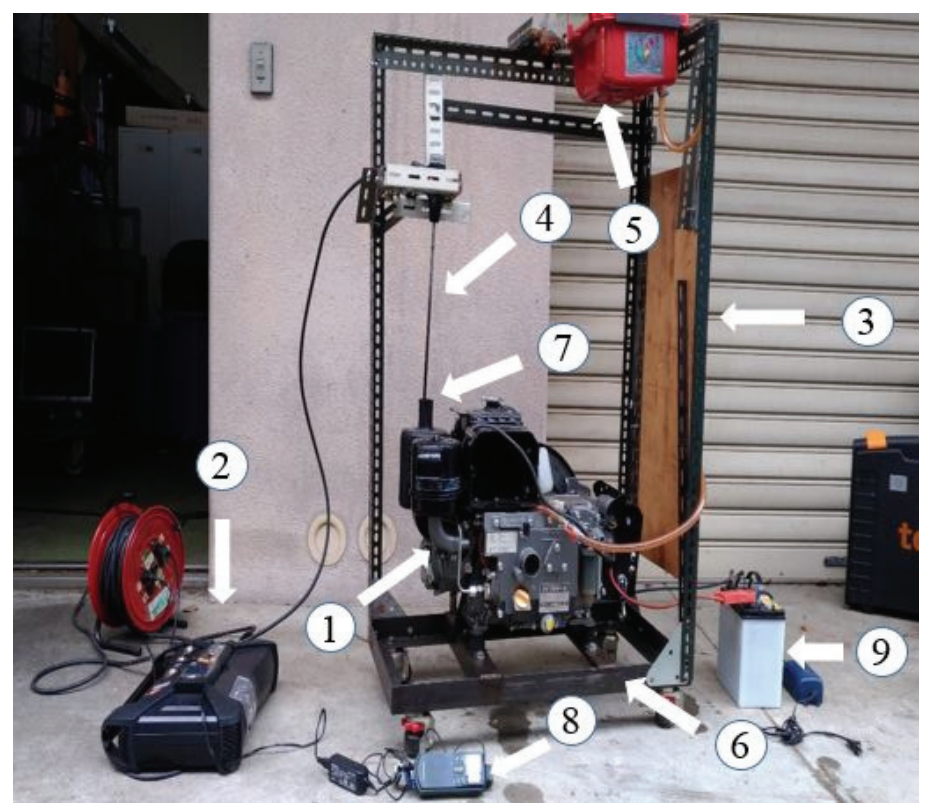

Fig. 1 Photographic view of the experimental setup (1: Yanmar Diesel Engine TF70V-E; 2: Testo 350 Flue gas analyser; 3: fuel consumption measurement system; 4: flue gas probe; 5: fuel tank; 6: engine support; 7: engine chimney; 8: digital Tachometer; 9: battery). 


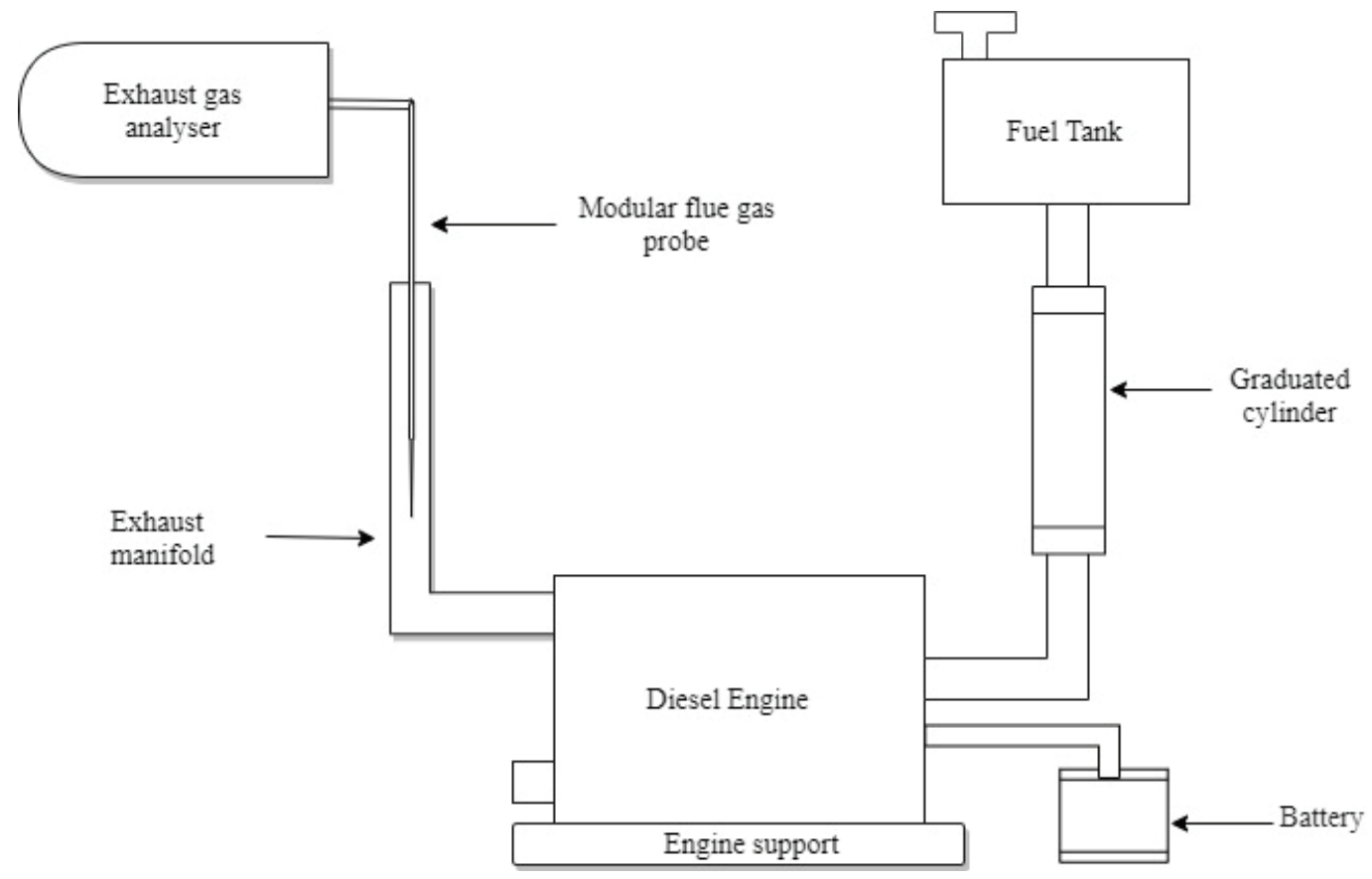

Fig. 2 Schematic diagram of experimental for engine test.

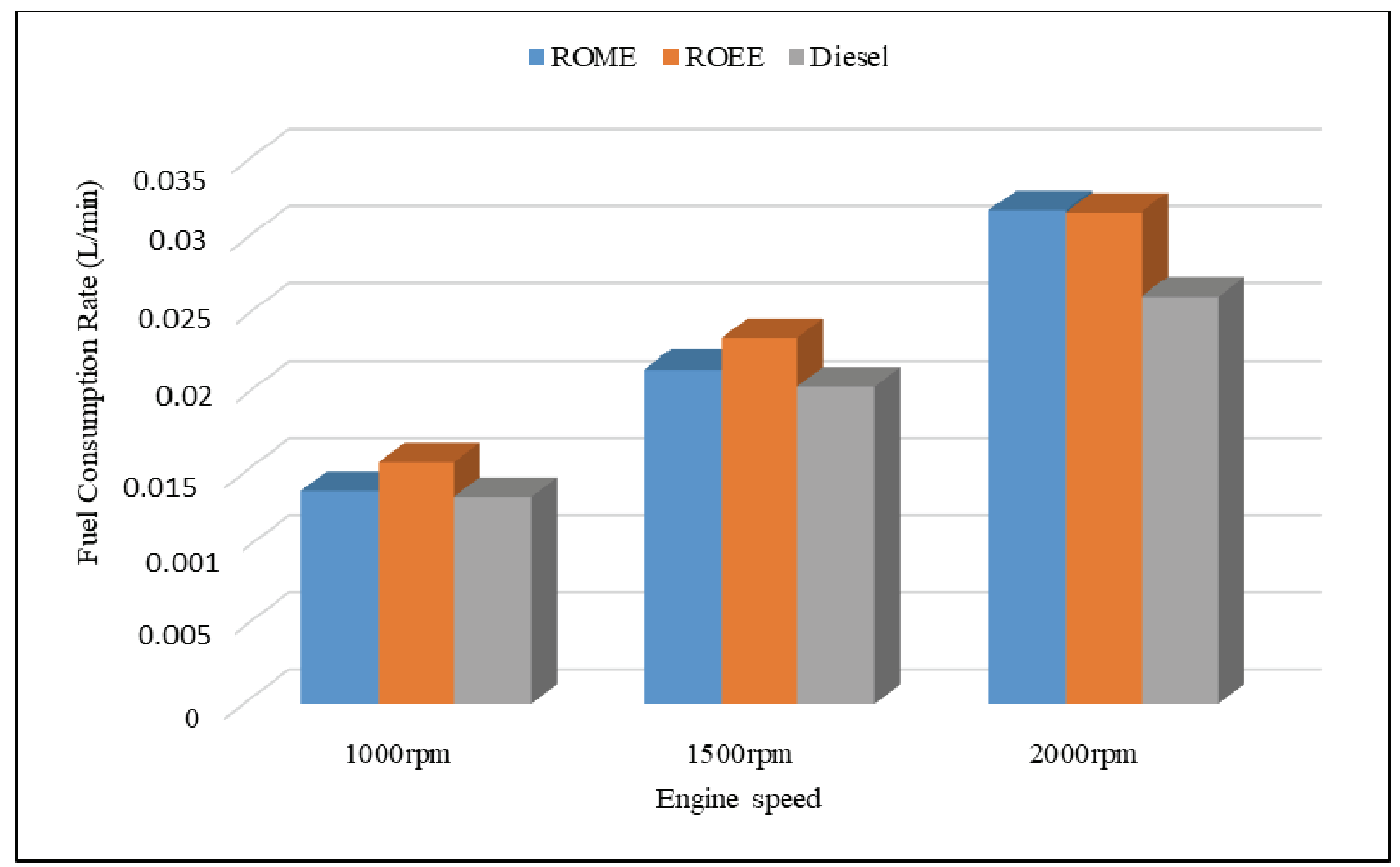

Fig. 3 Fuel consumption rate. 


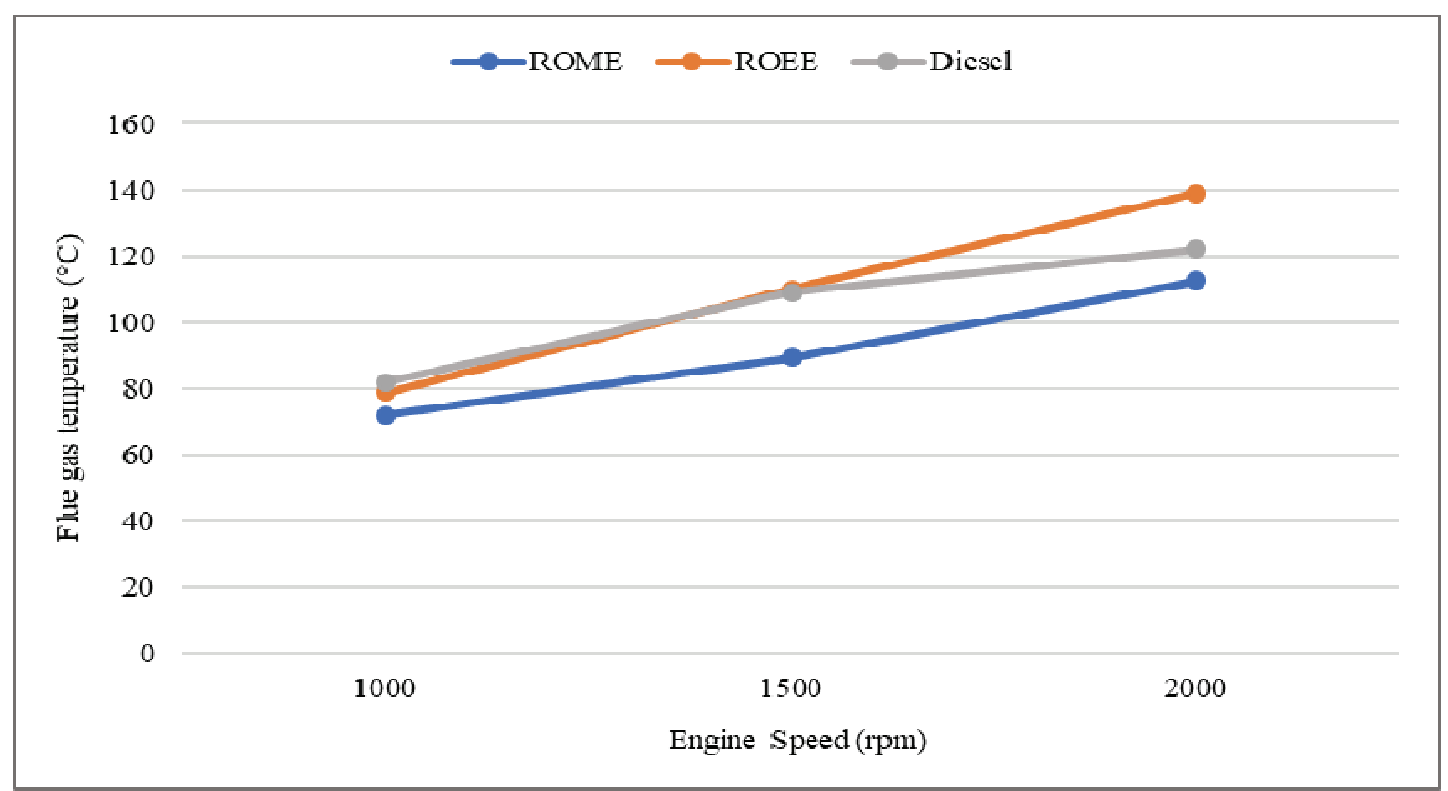

Fig. 4 FGT from diesel engine using biodiesel and diesel fuel under varied speed.

\subsection{Effect of Biodiesel on $\mathrm{NO}_{x}$ Emission}

Nitrogen oxides $\left(\mathrm{NO}_{x}\right)$ are the most significant environmental pollutants emitted from a diesel engine. In the presence of sunlight, it reacts with atmospheric oxygen to form a ground-level ozone which is the major smog component. Furthermore, in the presence of water, $\mathrm{NO}_{x}$ gas reacts with oxygen to form acid raining which directly affects human health (lung cancer) and threats certain ecosystems [39, 40].

$\mathrm{NO}_{x}$ emission profile of different tested fuels is shown in Fig. 5. It was found that the amount of $\mathrm{NO}_{x}$ released from fuels decreases when engine speed is increased. This is generally due to the shorter residence time available for $\mathrm{NO}_{x}$ formation, which may be the result of an increase both in the volumetric efficiency and flow velocity of the reactant mixture specifically at higher engine speed [41-43]. At low and medium engine speed, diesel fuel and ROEE produced maximum $\mathrm{NO}_{x}$ compared to ROME. This can be attributable to their higher FGT compared to ROME fuel. However, at high engine speed (2,000 rpm), $\mathrm{NO}_{x}$ emission from ROEE fuel becomes slightly higher than other tested fuels. This coincided to its highest FGT. So, the variation of $\mathrm{NO}_{x}$ is proportional to the FGT and is influenced by the nature of the fuel.
Generally, $\mathrm{NO}_{x}$ emission includes $\mathrm{NO}$ and nitrogen $\mathrm{NO}_{2}$. However, $\mathrm{NO}$ is the predominant oxide of nitrogen generated from the engine combustion. It contributes to ozone formation and it is considered as non-toxic gas by itself but it can threaten infants and sensitive individual $[40,44]$. Fig. 6 shows the $\mathrm{NO} / \mathrm{NO}_{x}$ ratio of the fuels under varied engine speed. The ratio follows a decreasing trend when engine speed is increased. This illustrates lower NO emission for all fuels but more reduced when using biodiesel at low engine speed.

\subsection{Effect of Biodiesel on $\mathrm{CO}$ and $\mathrm{CO}_{2}$ Emission}

Carbone monoxide (CO) is a poisonous gas generated by incomplete combustion process during diesel engine operation. This exhaust gas has severe effect on human health especially when it is breathed into the lungs [45]. In the presence of sufficient oxygen, it can be oxidized to $\mathrm{CO}_{2}$, which has a negative effect on the global warming [46, 47]. Emission characteristics of $\mathrm{CO}$ and $\mathrm{CO}_{2}$ from biodiesel and diesel fuel are depicted in Figs. 7 and 8, respectively. It can be seen that, CO emission from ROEE is continuously higher than other fuels and remains practically constant for any engine speed. This confirms that biodiesel based methyl esters emitted less CO compared to those based on ethyl esters [48]. 
Meanwhile, the trends of $\mathrm{CO}$ emission from ROME and diesel are constantly unstable with the variation of engine speed. In fact, when substituting diesel fuel with biodiesel many factors may influence significantly the variation of $\mathrm{CO}$ emission. Generally a decrease trend in $\mathrm{CO}$ emission is more evident even though some studies have found that $\mathrm{CO}$ emission from biodiesel is higher than of pure diesel fuel $[49,50]$. Even so, at low engine speed, CO emission from biodiesel fuels is higher compared to diesel fuel. This could be partly due to the poor atomization conditions influenced by the higher viscosity of biodiesel and the low FGT which leads to the high $\mathrm{CO}$ emission [51]. At medium engine speed, $\mathrm{CO}$ emission from ROME decreases and becomes the lowest compared to other fuels. In this case, it could be said that the molecular oxygen present in biodiesel, combined with the engine conditions at medium speed can be an ideal condition in the burning fuel at stoichiometric air-fuel mixture. This leads to a complete combustion of ROME and hence lowers its $\mathrm{CO}$ emission [23]. However, similar trend is not recorded from ROEE. The reason can probably come from the differences noticed in fuel properties of these two biodiesels.

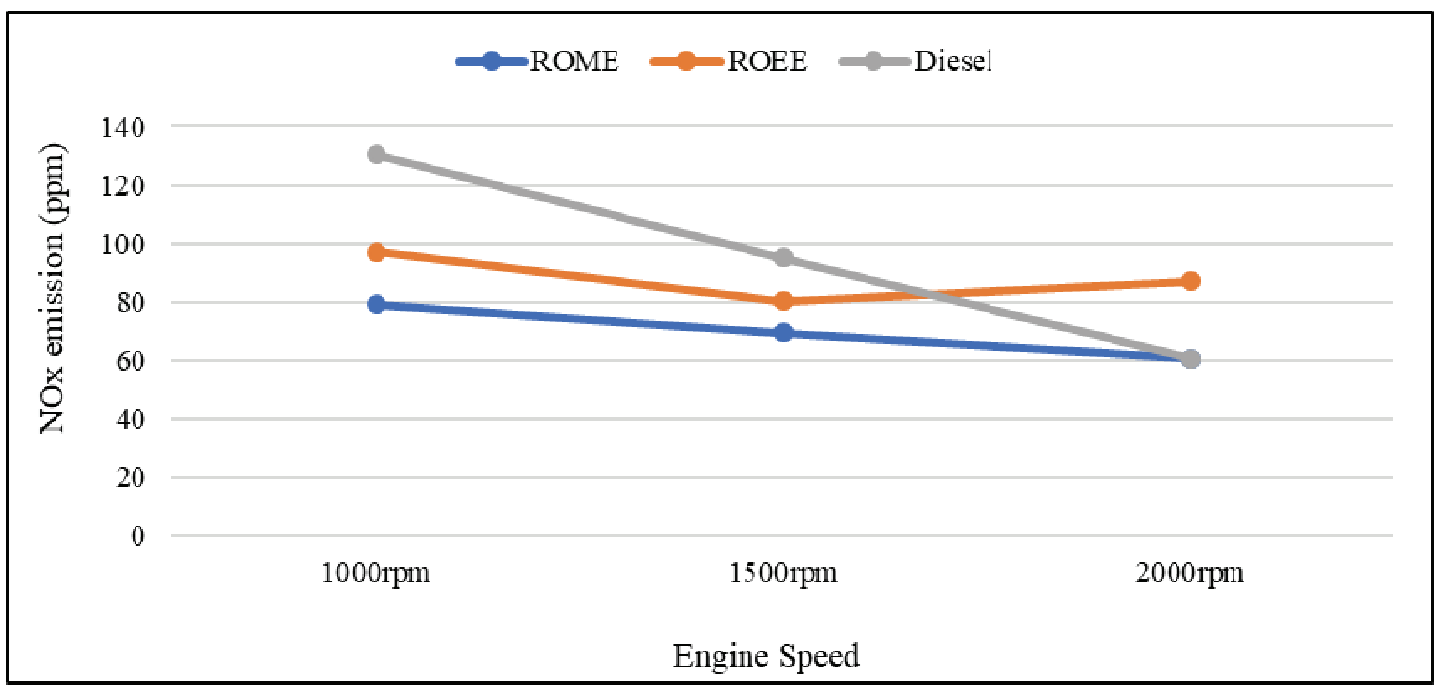

Fig. $5 \mathrm{NO}_{x}$ emission from diesel engine using biodiesel and diesel fuel under varied speed.

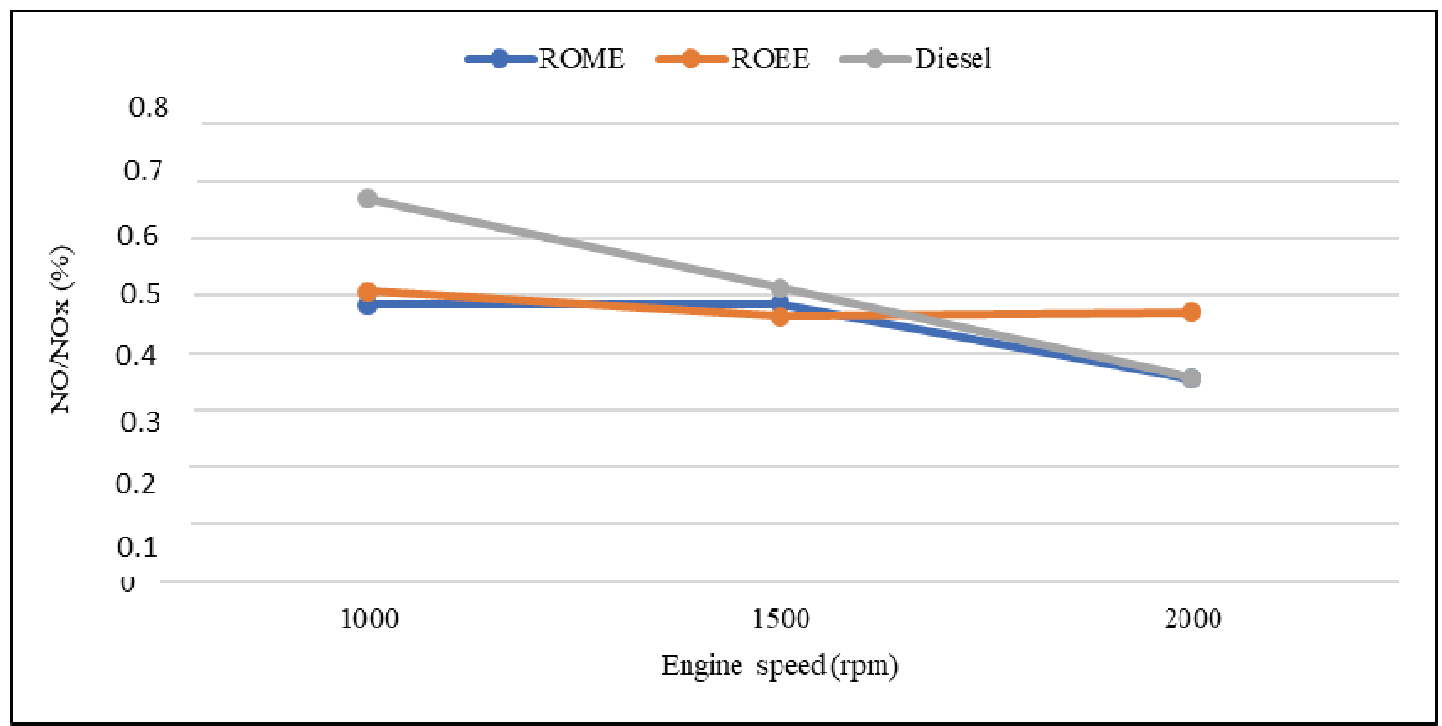

Fig. $6 \mathrm{NO} / \mathrm{NO}_{x}$ ratio of biodiesel and diesel fuels under varied speed. 


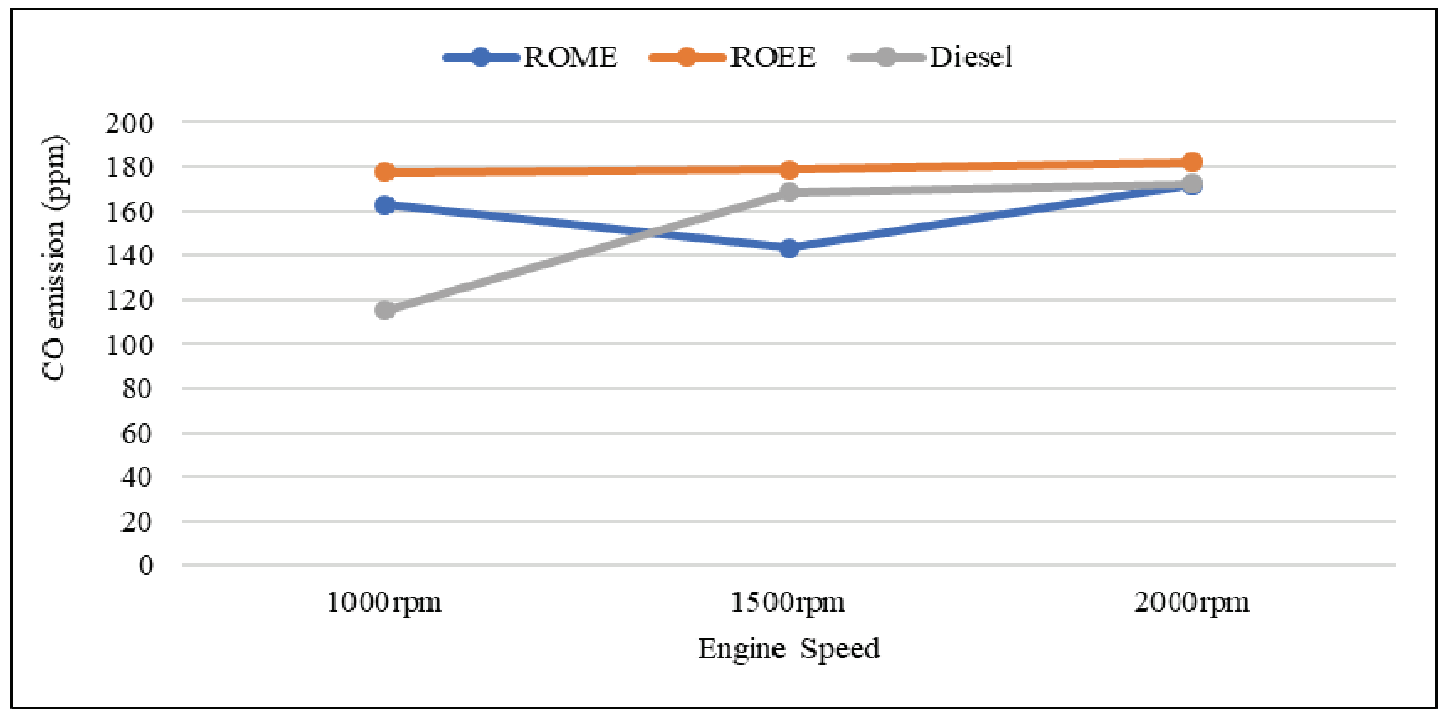

Fig. 7 CO emission from diesel engine using biodiesel and diesel fuel under varied speed.

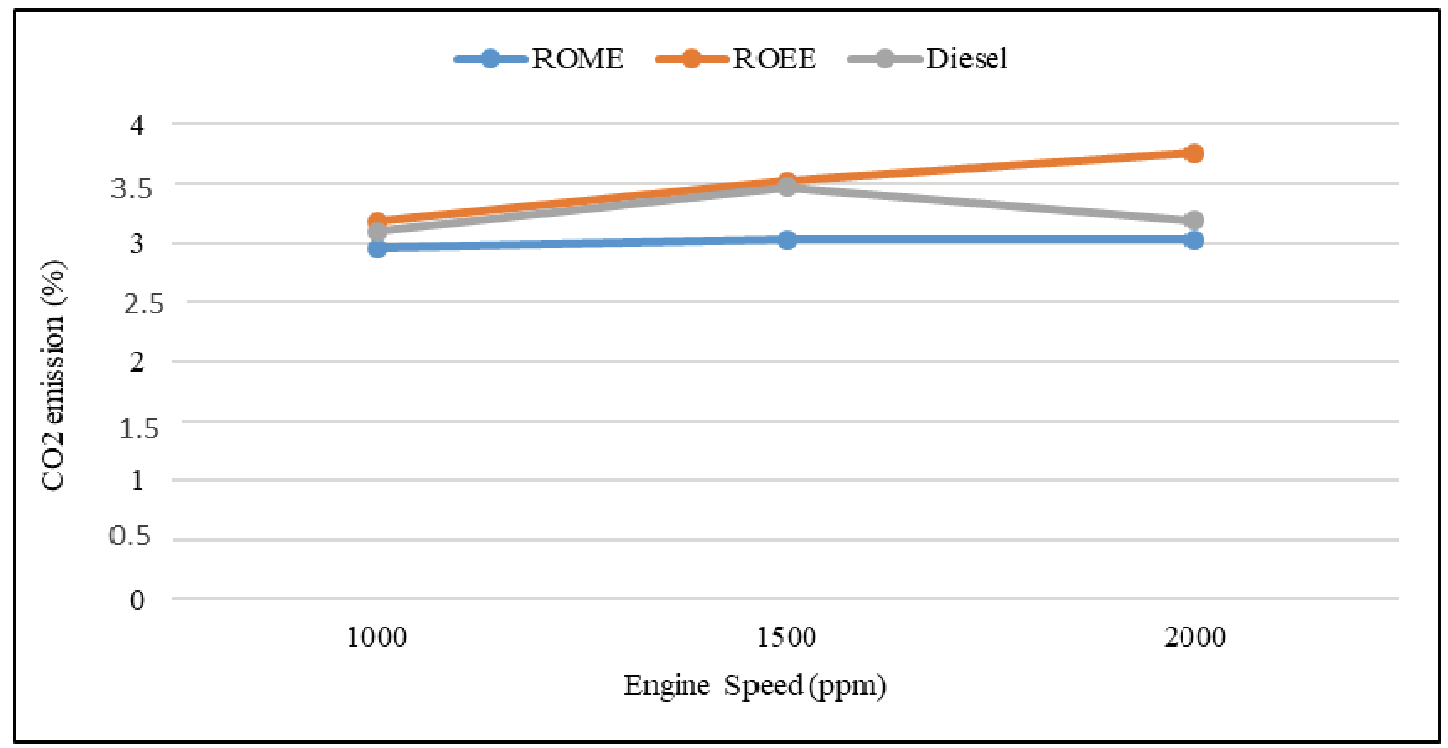

Fig. $8 \mathrm{CO}_{2}$ emission from diesel engine using biodiesel and diesel fuel under varied speed.

\section{Conclusion}

This study was focused on the investigation of engine performance and emission characteristics of two types of biodiesel produced from rapeseed oil. Results have shown that for all fuels tested, there is an increase in fuel consumption rate and exhaust gas temperature when the engine speed is increased. The variation profile of these parameters was more significant for normal diesel compared to biodiesel fuels. Exhaust emission gases such as $\mathrm{NO}_{x}$ and $\mathrm{NO}$ were reduced with the increase in engine speed in contrary $\mathrm{CO}$ and $\mathrm{CO}_{2}$ which were slightly increased. In comparison with diesel fuel, the biodiesel (ROME and ROEE) appeared to have higher fuel consumption rate because of their lower heating value and their oxygen content. ROME exhibited low emission gas compared to ROEE and mineral diesel as well. The results of this study proved that performance and exhaust emissions of a diesel engine using ROME and ROEE are reasonable. Thus, the optimization strategy used in the transesterification process is efficient to produce a quality biodiesel suitable for diesel engine. 


\section{Acknowledgment}

This work was supported by the JICA (Japan International Cooperation Agency) through the program of $\mathrm{ABE}$ Initiative (African Business Education Initiative for Youth) and the collaboration with Kumamoto University. We are so grateful to Thermal Engineering Laboratory for the use of their facilities.

\section{Reference}

[1] Mollenhauer, K., and Tschoeke, H. 2010. Handbook of Diesel Engines. Berlin Heidelberg: Springer-Verlag.

[2] Bacha, J., et al. 2007. Diesel Fuels Technical Review. San Ramon, USA: Chevron Corporation.

[3] Basha, S. A., Gopal, K. R., and Jebaraj, S. 2009. "A Review on Biodiesel Production, Combustion, Emissions and Performance." Renewable \& Sustainable Energy Reviews 13 (6): 1628-34.

[4] Bentley, R. W. 2002. "Global Oil \& Gas Depletion: An Overview." Energy Police 30: 189-205.

[5] Agarwal, A. K. 1998. "Vegetable Oil versus Diesel Fuel: Development and Use of Biodiesel in a Compression Ignition Engine." TERI Information Digest on Energy 8: 191-204.

[6] Gerling, P. 2007. "Reserves Resources and Availability of Energy, Hannover, Federal Institute for Geosciences and Natural Resources."

[7] Luque, R., and Melero, J. A. 2012. Advances in Biodiesel Production Processes and Technologies. UK: Woodhead Publishing Limited.

[8] DIN V 51605. 2006. "Fuels for Vegetable Oil Compatible Combustion Engines-Fuel from Rapeseed Oil-Requirements and Test Methods."

[9] Ahmad, M., Khan, M. A., Zafar, M., and Sultana, S. 2013. Practical Handbook on Biodiesel Production and Properties. Boca Raton, USA: CRC Press Taylor \& Francis Group.

[10] Freedman, B., and Pryde, E. H. 1984. "Variables Affecting the Yields of Fatty Esters from Transesterified Vegetable Oils." Journal of the American Oil Chemists' Society 61: 1638-43.

[11] Islam, A., and Ravindra, P. 2017. Biodiesel Production with Green Technologies. Switzerland: Springer International Publishing.

[12] Schuchardt, U., Sercheli, R., and Vargas, R. 1998. "Transesterification of Vegetable Oils: A Review." $J$. Braz. Chem. Soc. 9: 199-210.

[13] Pinto, A. C., Guarieiro, L. L. N., Rezende, M. J. C., Ribeiro, N. M., Torres, E. A., Lopes, W. A., Pereira, P. A., and de Andrade, J. B. 2005. "Biodiesel: An Overview." J Braz Chem Soc. 16: 1313-30.

[14] Meng, X., Chen, G., and Wang, Y. 2008. "Biodiesel Production from Waste Cooking Oil via Alkali Catalyst and Its Engine Test." Fuel Processing Technology 89: 851-7.

[15] Banapurmath, N. R., Tewari, P. G., and Hosmath, R. S. 2009. "Effect of Biodiesel Derived from Honge Oil and Its Blends with Diesel When Directly Injected at Different Injection Pressures and Injection Timings in Single-Cylinder Water-Cooled Compression Ignition Engine." Proc. Inst. Mech. Eng. 223: 31-40.

[16] Dincer, K. 2008. "Lower Emissions from Biodiesel Combustion." Energy Sources Part A-Recovery, Utilization and Environmental Effects 30 (10): 963-8.

[17] Kalligeros, S., Zannikos, F., Stournas, S., Lios, E., Anastopoulos, G., Teas, C., et al. 2003. "An Investigation of Using Biodiesel/Marine Diesel Blends on the Performance of a Stationary Diesel Engine." Biomass and Bioenergy 24: 141-9.

[18] Usta, N. 2005. “An Experimental Study on Performance and Exhaust Emissions of a Diesel Engine Fueled with Tobacco Seed Oil Methyl Ester." Energy Conversion and Management 46: 2373-86.

[19] Lapuerta, M., Herreros, J. M., Lyons, L. L., Garía-Contreras, R., and Briceño, Y. 2008. "Effect of the Alcohol Type Used in the Production of Waste Cooking Oil Biodiesel on Diesel Performance and Emissions." Fuel 87 (15): 3161-9.

[20] Carraretto, C., Macor, A., Mirandola, A., Stoppato, A., and Tonon, S. 2004. "Biodiesel as Alternative Fuel: Experimental Analysis and Energetic Evaluations." Energy 29: 2195-211.

[21] Xue, J., Grift, T. E., and Hansen, A. C. 2011. "Effect of Biodiesel on Engine Performances and Emissions." Renewable \& Sustainable Energy Reviews 15 (2): 1098 116.

[22] Ozsezen, A. N., Canakci, M., Turkcan, A., and Sayin, C. 2009. "Performance and Combustion Characteristics of a DI Diesel Engine Fueled with Waste Palm Oil and Canola Oil Methyl Esters." Fuel 88: 629-36.

[23] Ramadhas, A. S., Muraleedharan, C., and Jayaraj, S. 2005. "Performance and Emission Evaluation of a Diesel Engine Fueled with Methyl Esters of Rubber Seed Oil." Renewable Energy 30: 1789-800.

[24] Iranmanesh, M., Subrahmanyam, J., and Babu, M. 2008. "Potential of Diethyl Ether as a Blended Supplementary Oxygenated Fuel with Biodiesel to Improve Combustion and Emission Characteristics of Diesel Engines." SAE Technical Paper 1: 1805.

[25] Utlu, Z., and Kocak, M. S. 2008. "The Effect of Biodiesel Fuel Obtained from Waste Frying Oil on Direct Injection 
Diesel Engine Performance and Exhaust Emissions." Renewable Energy 33: 1936-41.

[26] Hansen, A. C., Gratton, M. R., and Yuan, W. 2006. "Diesel Engine Performance and $\mathrm{NO}_{x}$ Emissions from Oxygenated Biofuels and Blends with Diesel Fuel.” Trans. ASABE 49: 589-95.

[27] Lapuerta, M., Armas, O., and Herreros, J. M. 2008. "Emissions from a Diesel-Bioethanol Blend in an Automotive Diesel Engine." Fuel 1: 25-31.

[28] Rajak, U., and Verma, T. N. 2020. "Influence of Combustion and Emission Characteristics on a Compression Ignition Engine from a Different Generation of Biodiesel." Engineering Science and Technology, an International Journal 23: 10-20.

[29] Shrivastava, P., and Verm, T. N. 2020. “An Experimental Investigation into Engine Characteristics Fueled with Lal Ambari Biodiesel and Its Blends.” Thermal Science and Engineering Progress 17.

[30] Yesilyurt, M. K., Yilbasi, Z., and Aydin, M. 2020. “The Performance, Emissions, and Combustion Characteristics of an Unmodified Diesel Engine Running on the Ternary Blends of Pentanol/Safflower Oil Biodiesel/Diesel Fuel." Journal of Thermal Analysis and Calorimetry 140: 2903-42.

[31] Dieng, M. T., Iwanaga, T., Yurie, Y. C., and Torii, S. 2019. "Production and Characterization of Biodiesel from Rapeseed Oil through Optimization of Transesterification Reaction Conditions." Journal of Energy and Power Engineering 13: 380-91.

[32] Lin, C. Y., and Wang, K. H. 2004. "Diesel Engine Performance and Emission Characteristics Using Three-Phase Emulsions as Fuel." Fuel 83: 537-45.

[33] Mccarthy, P., Rasul, M. G., and Moazzem, S. 2011. "Comparison of the Performance and Emissions of Different Biodiesel Blends against Petroleum Diesel." International Journal of Low-Carbon Technologies 6 (4): 255-60.

[34] Tan, P. Q., Hu, Z. Y., Lou, D. M., and Li, Z. J. 2012. "Exhaust Emissions from a Light-Duty Diesel Engine with Jatropha Biodiesel Fuel." Energy 39: 356-62.

[35] Lin, C. Y., and Lin, H. A. 2006. "Diesel Engine Performance and Emission Characteristics of Biodiesel Produced by the Peroxidation Process." Fuel 85: 298-305.

[36] Ramadhas, A. S., and Jayaraj, C. M. S. 2008. "Reduction in Exhaust Gas Temperature of Biodiesel Fueled Engine by Exhaust Gas Recirculation." Clean 36: 978-83.

[37] Gad, M. S., El-Araby, R., Abed, K. A., El-Ibiari, N. N., El Morsi, A. K., and El-Diwani, G. I. 2018. "Performance and Emissions Characteristics of C.I. Engine Fueled with Palm Oil/Palm Oil Methyl Ester Blended with Diesel Fuel.” Egyptian Journal of Petroleum 27: 215-9.
[38] Kegl, B., Kegl, M., and Pehan, S. 2013. Green Diesel Engines, Biodiesel Usage in Diesel Engines. London: Springer-Verlag.

[39] Bari, S. 2013. Diesel Engine-Combustion, Emissions and Condition Monitoring. Croatia: InTech.

[40] Clean Air Technology Center (MD-12). 1999. "Nitrogen Oxides $\left(\mathrm{NO}_{x}\right)$, Why and How They Are Controlled." EPA-456/F-99-006R.

[41] Sarin, A. 2012. Biodiesel Production and Properties. UK: Royal Society of Chemistry.

[42] Lin, C., and Lin, H. 2007. "Engine Performance and Emission Characteristics of a Three-Phase Emulsion of Biodiesel Produced by Peroxidation." Fuel Processing Technology 88: 35-41.

[43] Lin, C. Y., and Li, R. Y. 2009. "Engine Performance and Emission Characteristics of Marine Fish-Oil Biodiesel Produced from the Discarded Parts of Marine Fish." Fuel Processing Technology 90: 883-8.

[44] Gordon, T., Stanek, L. W., and Brown, J. 2014. "Pollution, Air in Encyclopedia of Toxicology." Encyclopedia of Toxicology (Third Edition) 3: 995-1002.

[45] Chamberlain, O. 2016. "Carbon-Monoxide (CO): A Poisonous Gas Emitted from Automobiles, Its Effect on Human Health." Adv. Automob Eng. 5: 151-8.

[46] Prakash, R., Singh, R. K., and Murugan, S. 2015. "Experimental Studies on Combustion, Performance and Emission Characteristics of Diesel Engine Using Different Biodiesel Bio Oil Emulsions." J Energy Inst. 88: 64-75.

[47] Kegl, B., Kegl, M., and Stanislav, P. 2013. Green Diesel Engines, Lecture Notes in Energy, Vol. 12. London: Springer-Verlag.

[48] Baiju, B., Naik, M. K., and Das, L. M. 2009. "A Comparative Evaluation of Compression Ignition Engine Characteristics Using Methyl and Ethyl Esters of Karanja Oil." Renewable Energy 34: 1616-21.

[49] Cardone, M., Prati, M. V., Rocco, V., Seggiani, M., Senatore, A., and Vitolo, S. 2002. "Brassica carinata as an Alternative Oil Crop for the Production of Biodiesel in Italy: Engine Performance and Regulated and Unregulated Exhaust Emissions.” Environ Sci. Technol. 36: 4656-62.

[50] Fontaras, G., Karavalakis, G., Kousoulidou, M., Tzamkiozis, T., Ntziachristos, L., Bakeas, E., et al. 2009. "Effects of Biodiesel on Passenger Car Fuel Consumption, Regulated and Non-regulated Pollutant Emissions over Legislated and Real-World Driving Cycles.” Fuel 88 (9): 1608-17.

[51] Krahl, J., Knothe, G., Munack, A., Ruschel, Y., Schröder, O., Hallier, E., et al. 2009. "Comparison of Exhaust Emissions and Their Mutagenicity from the Combustion of Biodiesel, Vegetable Oil, Gas-to-Liquid and Petrodiesel Fuels." Fuel 188: 1064-9. 